\title{
A Arquidiocese de Cuiabá ontem e hoje: perspectivas pastorais
}

The Archdiocese of Cuiabá today and today: pastoral perspectives

La Arquidiócesis de Cuiabá ayer y hoy: perspectivas pastorales

João dos Santos Barbosa Neto ${ }^{1}$

${ }^{1}$ Sacerdote Salesiano. Licenciado em Filosofia (UCDB/MS); Bacharel em Teologia (UPS/ITÁLIA); Pós-graduado lato sensu em Counseling (IATES/PR); Pós-graduado latu senso em Psicopedagogia (UCDB/Portal Educação); Mestre e Doutorando em Teologia Pastoral pela Università Pontificia Salesiana (UPS), Itália. E-mail: joaoneto@missaosalesiana.org.br 
Resumo: Esta pesquisa visa proceder na apresentação histórica, social e pastoral da Arquidiocese de Cuiabá, a partir da época em que era uma capelania da Arquidiocese de Rio de Janeiro até o seu estado atual. É relevante o desenvolvimento progressivo das práticas religiosas do povo cuiabano e a consolidação da presença da Igreja Católica, que determina, por meio de seu calendário religioso, o ritmo da vida do povo. Toda a história, devidamente documentada, é narrada através dos olhares dos bispos e arcebispos que conseguiram obter respostas significativas ao próprio tempo e colaboraram na formação e identificação dos cidadãos de Cuiabá em um povo com tradições e valores cristãos. Nessa linha, seguem as atuais ações pastorais da Arquidiocese; com uma linguagem moderna, esforçam-se para continuar sendo essa luz divina capaz de iluminar o coração de seu povo em um tempo de crise e de dificuldades.

Palavra-chave: Arquidiocese de Cuiabá; pastoral; história arquidiocesana.

\begin{abstract}
This research aims to make an historical, social and pastoral presentation of the Archdiocese of Cuiaba, from when it was a chaplaincy of the Archdiocese of Rio de Janeiro to its current state. It is relevant the progress development of the religious practices of the people and the consolidation of the presence of the Church that determinates with its religious calendar the rhythm of the life of the people. The whole story, duly documented, is told through the eyes of bishops and archbishops who have given significative answers to their time and collaborated in the formation and identification of the citizens of Cuiabá with their Christian traditions and values. In this line the pastoral action of the Archdiocese are followed, which with a modern language strives to continue being that divine light capable of illuminate the heart of its people in a time of crisis and difficulties.
\end{abstract}

Keywords: Archdiocese of Cuiabá; pastoral theology; archdiocesan history.

Resumen: Esta investigación pretende hacer una presentación histórica, social y pastoral de la Arquidiócesis de Cuiabá, de cuando era una capellanía de la Arquidiócesis de Río de Janeiro hasta su estado actual. Es relevante el progresivo desarrollo de las prácticas religiosas del Pueblo cuiabano y la consolidación de la presencia de la Iglesia que determina por medio de su calendario religioso el ritmo de la vida del pueblo. Toda la historia, debidamente documentada y narrada a través de los ojos de los obispos y arzobispos que conseguirán dar respuestas significativas al propio tiempo y colaborarán con la formación e identificación de los ciudadanos de Cuiabá en sus tradiciones y valores cristianos. En esta línea se siguen las actuales acciones pastorales de la Arquidiócesis, que con un lenguaje moderno se esfuerza en continuar siendo esa luz divina capaz de iluminar el corazón de su pueblo en un tiempo de crisis y de dificultades.

Palabras clave: Arquidiócesis de Cuiabá; teología pastoral; historia arquidiocesana. 


\section{INTRODUÇÃO}

Este artigo pretende servir como uma contribuição científica e acadêmica referente à presença da Igreja Católica na celebração jubilar dos 300 anos da fundação da cidade de Cuiabá. Tanto a história da cidade quanto a história da arquidiocese são intrinsecamente unidas e se confundemao longo desse bonito percurso, mesmo que consolidado, ainda em vias de caminho. Os traços constituintes que caracterizam o povo cuiabano receberam uma forte influência religiosa, vinculando-os a uma experiência de fé e de sagrado que perdura até os dias atuais. Nessa sociedade, os fatos (públicos e particulares) e políticos foram, e continuam sendo, vividos pela sociedade civil, mas é notório que essa mesma sociedade sente a necessidade, na verdade uma exigência, em celebrá-los pelo cunho religioso.

Foi a experiência da piedade popular celebrada nos bairros por meio das capelas paroquiais que ditaram o ritmo de vida, das festas e das relações desse povo, que foi se formando nas tradições religiosas e na partilha de comunidade. Foi também ao redor dos arcebispos os quais se sucederam na arquidiocese que as pessoas se identificavam e se enchiam de esperança, pois sempre encontraram neles, os braços que acolhiam as milhares de famílias que vinham para Cuiabá em busca de trabalho e oportunidades; bem como, encontravam também, a voz profética que, sem medo, denunciava os problemas: na saúde, na segurança, e a corrupção que, em detrimento de tantos sem recursos, beneficia alguns privilegiados.

No presente momento em que a sociedade cuiabana realiza diversos eventos para comemorar o aniversário de sua cidade, é oportuno ter esse olhar profundo em suas raízes históricas e religiosas para melhor compreender respeitosamente o passado, entender o hoje e projetar com responsabilidade o amanhã. Busca-se, nessas laudas, exibir uma linha histórica e progressiva do crescimento e desenvolvimento da Arquidiocese; apresentar e caracterizar os bispos e arcebispos que se sucederam até o presente momento; identificar e fornecer documentos bibliográficos relevantes desse processo; demonstrar que a constituição da sociedade cuiabana se identifica com a presença forte e carismática da Arquidiocese; e, por fim, apresentar o quadro atual da pastoral da Arquidiocese. 


\section{A ORIGEM: O VILAREJO E A CAPELANIA}

Inicia-se fazendo a apresentação da história do pequeno vilarejo que recebeu os primeiros missionários. Posteriormente, a partir da presença dos primeiros religiosos, percorrer-se-á das etapas do desenvolvimento pastoral da capelania à fundação da Arquidiocese de Cuiabá até os dias atuais.

\subsection{Uma história de suor e sangue}

A cidade de Cuiabá teve a sua origem com a chegada dos bandeirantes que avançavam o interior do país em um processo de expansão das fronteiras. A presença de ouro na região atraía pessoas para trabalharem em campos de mineração.

No ano de 1673 a cidade de Cuiabá era um povoado fundado por Manoel de Campos Bicudo nas proximidades do rio Coxipó, mais precisamente onde o rio Coxipó deságua no rio Cuiabá. Em 1718, o local estava abandonado e Pascoal Moreira Cabral que buscava indígenas subiu pelo rio Coxipó lutando com os índios coxiponés. Ao voltar da batalha encontraram ouro e fez com que desistissem da captura dos índios para se dedicar ao garimpo. Em 08 de Abril de 1719, Pascoal assinou a ata de fundação de Cuiabá num local conhecido como Forquilha. Em 1ㅇ de Janeiro de 1727, Cuiabá é elevada à vila passando a se chamar Vila Real do Senhor Bom Jesus de Cuiabá e elevada à cidade em 17 de Setembro de 1818 tornando-se capital do estado em 28 de Agosto de 1835. (BRASIL ESCOLA, s.d.).

É nesse contexto interiorano, de misturas raciais, com fortes tradições folclóricas, onde se misturam os interesses nacionalistas e comerciais, que desponta o que virá a ser um centro urbano moderno e atrativo no coração do Brasil. Cuiabá, desde suas origens, possui uma forte ligação com o Divino e a sua religiosidade ancorada na vida das pessoas, passados quase três séculos, continua robusta e vibrante.

Consta no ato de fundação da cidade em 1719, a invocação à intercessão de Nossa Senhora da Penha da França. Provavelmente a manutenção da fé católica era mantida pelos fiéis em suas práticas devocionais transmitidas de pais para filhos. O relato de primeiros sacerdotes nessa área remete ao ano de 1721: 
Chegou o Padre Frei Florêncio dos Anjos, religioso carmelita, o Padre Jerônimo Botelho, do hábito de São Pedro, o Padre André dos Santos Queiroz, do hábito de São Pedro, o Padre Frei Francisco dos Anjos, franciscano. Chegados ao arraial que é hoje a Capela de São Gonçalo, mudaram-se todos para o Coxipó acima, lugar chamado hoje a Forquilha, onde formaram Arraial e levantaram Igreja com o título de Nossa Senhora da Penha da França. Celebraram-se ofícios divinos sendo que o primeiro que fez vezes de capelão, por eleição comum, o Padre Jerônimo Botelho e depois o Padre André dos Santos Queiroz. (COMETTI, 1996, p. 9).

Era a Diocese de São Sebastião do Rio de Janeiro a responsável territorial desta nova cidade. E já em 1722, o bispo Dom Frei Francisco de São Jerônimo envia o primeiro vigário: Padre Francisco Justo, hábito de São Pedro. Assim Cometti (1996, p. 12) narra o episódio:

Neste mesmo ano levantou o Capitão Mor Jacinto Barbosa Lopes uma igreja à sua custa, coberta de palha, que logo serviu de freguesia no mesmo lugar em que se acha a que existe atualmente dando-lhe o título de Igreja do Senhor Bom Jesus de Cuiabá. Consequentemente levantaram os pretos uma Capelinha a São Benedito.

A Matriz do povoado tornou-se, como era comum em seu tempo, o ponto forte onde as pessoas se reuniam, faziam feiras e festas com danças e comidas. Mas a Matriz, ao longo do tempo, "passou por reformas, reconstruções, ganhou uma segunda torre, deixou de ser Matriz para passar a ser Catedral. Mas a maior transformação ocorreu em 14 de agosto de 1968, quando a igreja foi destruída por duas descargas de dinamite" (MENDES, s.d.), devido às péssimas condições físicas em que se encontravam as paredes do lado esquerdo da Igreja.

A imagem que se encontra hoje na Catedral de Cuiabá remonta ao ano de 1729 e se encontrava em um sítio de Camapuã, MS. Não se sabe quem foi a artista da imagem, o que se sabe é que ela foi feita de madeira pelas mãos de uma mulher na vila de Sorocaba, SP:

Trouxe-a consigo Pedro de Morais, natural de Sorocaba-SP, nos primeiros anos que estes sertões foram colonizados e, não podendo continuar a jornada pelas dificuldades que naquela havia, deixou a imagem dentro de um caixão, em um rancho coberto de palha bacuri, à borda do Rio Grande, em um lugar chamado Guarapiranga, 
onde deixou também uma cabra que trazia e que se conservava no mesmo rancho a imagem. Chegando a Vila, foi a imagem levada à Matriz e colocada em um altar colateral do lado do Evangelho. Ao mesmo tempo em que o faziam, entraram com o cadáver de Pedro de Morais, aquele que havia mandado trazê-la. (COMETTI, 1996, p. 18).

No ano de 1734, durante a Guerra dos Paiaguás, a Vila Real do Senhor Bom Jesus de Cuiabá, como era chamada a cidade de Cuiabá, participa ativamente com soldados e equipamentos. Para dar o suporte espiritual aos combatentes, partiram os capelães, o PadreFrei Pacífico dos Anjos, religioso franciscano, e o Padre Manuel de Campos Bicudo, do hábito de São Pedro, com todos os paramentos da missa, celebrada dentro das balsas, conforme relata Cometti (1996). Essa Guerra aconteceu na região do Estado de Mato Grosso, e a carnificina retratada pelos testemunhos da guerra constatam a dificuldade de integração com os indígenas da região, quando este não se subordinavam aos apelos dos colonizadores:

Teve como resultado mais de 600 índios mortos. Tiveram as cabeças decepadas e penduradas em estacas, para que fossem considerados um exemplo. A guerra foi considerada justa, e tinha a permissão do rei. Osdonos de engenhos e colonos colaboravam com recursos. Nesta guerra, ao lado de Portugal, estavam os índios bororos. Não foram manipulados. A guerra era de interesse deles. Os índios paiaguás estavam, na época, deixando gradativamente a Bacia do Prata. Hoje os paiaguás estão extintos. Os poucos sobreviventes morreram de tanto beber. O alcoolismo também foi uma arma usada naquela época pelos colonizadores. Os índios perdiam a força. (DIÁRIO DE CUIABÁ, s.d.).

O Estado de Mato Grosso aos poucos ia sendo expandido, outros povoados iam se formando. Ciente desse avanço, Dom Frei Antônio de Guadalupe, em março de 1737, nomeia o Padre José Pereira de Aranda, do hábito de São Pedro, como Capelão dos descobrimentos de Mato Grosso. Padre João Caetano era, desde 1735, o Vigário da Vara e, com a chegada do novo capelão, organizaram-se em comum acordo com o bispo da seguinte forma: "a Vila Real do Senhor Bom Jesus de Cuiabá continua a ser a sede do Vigário da Vara, superior imediato do vigário de Mato Grosso" (COMETTI, 1996, p. 21).

A Igreja, por meio seus missionários, acompanhou esse avanço dos desbravadores ao centro do Brasil. Mesmo que os ideais dos colonizadores 
fossem econômicos e, por isso, dizimavam os índios que ali estavam, a presença dos missionários era uma tentativa de dar o suporte espiritual às comunidades que iam se formando e, ao mesmo tempo, tinha esse caráter de evangelização com as tribos que iam tendo contato com os 'brancos'.

\subsection{A fundação da Arquidiocese}

Foram necessários 72 anos, desde a chegada do primeiro sacerdote enviado pela Diocese de São Sebastião do Rio de Janeiro às terras de Mato Grosso, para que a região fosse elevada ao título de Prelazia. Eis que, em 6 de dezembro de 1745, o Papa Bento XIV (1890), com a Bula Candor Lucis Aeternae, no capítulo intitulado "De divisione disponit territori Episcopatus Fluminis Ianuarii in Brasilia, et nova erectione Episcopatuum Mariannensis et Sancti Pauli; nec non praelaturarum Goiasinsis et Cuiabaensis etiam in Brasilia", criou a Prelazia de Cuiabá.

Entende-se por prelazia "uma determinada porção do povo de Deus, territorialmente delimitada, cujo cuidado, por circunstâncias especiais, é confiado a um Prelado, que a governa como seu próprio pastor, à semelhança do Bispo diocesano" (CONGREGAÇÃO DA DOUTRINA DA FÉ, 2001, can. 370). E, neste caso, esta prelazia possuía uma extensão de aproximadamente 1.400 .000 km², correspondente aos atuais territórios de Mato Grosso, Mato Grosso do Sul e de Rondônia.

A distância das regiões mais povoadas brasileiras e a falta de conhecimento da realidade em terras mato-grossenses foi o grande motivo para rejeição de vários candidatos ao cargo de Prelado de Cuiabá. A prelazia, instituída em 1745, teve sede vacante até o ano de 1782, nesse período se sucederam diversos vigários, mas nenhum com o título de prelado.

\subsubsection{Primeiro prelado Dom José Nicolau de Azevedo Coutinho Gentil}

De acordo com o Arquivo da Cúria Metropolitana de Cuiabá (1967), Dom José Nicolau de Azevedo Coutinho Gentil, no ano de 1782, foi o primeiro prelado nomeado, mas não tomou posse. O segundo governo de prelado aconteceu de 1809 a 1821, com Dom Luiz de Castro Pereira. 
Com a morte de Dom Luiz, o seu sucessor, o missionário capuchinho Frei José Maria Macerata, que residia e já trabalhava com o povo na prelazia, tornou-se o responsável pela administração da Prelazia de Cuiabá. O Brasil nesse período atravessava uma onda de "nacionalismo exacerbado que antecederam e se seguiram ao evento da independência, os quais, também repercutiram no terreno religioso. Frei Macerata foi desprestigiado e até mesmo combatido por ser estrangeiro, acabando por ser destituído de sua investidura prelatícia" (PÓVOAS, 1995, p. 187). O Frei Macerata administrou a Prelazia de Cuiabá de 1823 a 1831. E participou da elevação da Prelazia à Diocese de Cuiabá, mas, por questões políticas, não foi ordenado bispo.

O Papa Leão XII (1854), no dia 15 de julho de 1826, com a Bula Sollicita Catholici Gregis Cura, no capítulo intitulado 'Praelaturae Gojasensis et Cujabaensis nuncupatae in sedes episcopales eriguntur', tornou a Prelazia de Cuiabá como Diocese de Cuiabá.

Como Diocese, a Igreja entende "a porção do Povo de Deus confiada ao pastoreio do Bispo com a cooperação do presbitério, de modo tal que, unindo-se ela a seu pastor e, pelo Evangelho e pela Eucaristia, reunida por ele no Espírito Santo, constitua uma Igreja particular, na qual verdadeiramente presente e operante a Igreja de Cristo una, santa, católica eapostólica" (CONGREGAÇÃO DA DOUTRINA DA FÉ, 2001, can. 369).

A alegria da criação da nova Diocese contrasta com a perseguição política que sofria o vigário da prelazia e, consequentemente, o vigário da neo Diocese. Porém, conforme relata Póvoas (1995), a unidade e a solidariedade da Igreja abraçaram e sustentaram o Frei Macerata. A nomeação daquele que seria o primeiro Bispo desta diocese, partiu de um Decreto Imperial, datado de 08 de outubro de 1828 e aceito pelo Vaticano. Mas o escolhido à Monsenhor da Capela Imperial Plácido Mendes Carneiro renunciou a função.

\subsubsection{Enfim, o primeiro Bispo Dom José Antônio dos Reis}

A diocese recebeu com alegria a notícia da nomeação de seu primeiro bispo, no ano de 1831. A nomeação do Cônego José Antônio dos Reis partiu de um Decreto da Regência do país, no dia 27 de agosto de 1831. Porém Póvoas (1995) diz que, somente em 2 de junho de 1832, o Vaticano confirmou a escolha, e, no dia 8 de dezembro, deste mesmo ano, na Catedral 
de São Paulo, houve a missa de Sagração Episcopal. Dom José Antônio dos Reis "chegou em Cuiabá a 27 de novembro de 1833. Foi uma das figuras mais brilhantes do clero brasileiro, cuja contribuição para o desenvolvimento cultural de Mato Grosso foi decisiva" (PÓVOAS, 1995, p. 189).

Dom José governou por 45 anos a diocese, falecendo aos 78 anos, aos 11 de novembro de 1876. Nesse período, destaca-se a construção do Seminário da Conceição, "que era a primeira escola de nível médio que existiu na Província, o ano letivo de 1854 como um estabelecimento oficial" (PÓVOAS, 1995, p. 190).

\subsubsection{Segundo Bispo e primeiro Arcebispo Dom Carlos Luiz D’Amour}

Foram dois anos de sede vacante até a nomeação do Padre Carlos Luiz D’Amour como bispo de Cuiabá, em 21 de setembro de 1877, e foi sagrado, dia 28 de abril de 1878, por Dom Joaquim Gonçalves de Azevedo, Arcebispo de São Salvador da Bahia. Governou por 43 anos, de 1878 a 1921, sendo também o primeiro Arcebispo da Diocese.

A elevação da Diocese à categoria de Arquidiocese de Cuiabá, realizou-se no dia 5 de abril de 1910 por meio da Bula Novas Constituire do Papa Pio X (1910), com o título: "10 martii 1910 - In metropolitam evexit sedem episcopalem Cuiabensem eique suffraganeas constituit duas novas sedes episcopales S. Aloisii de Cáceres et Corumbensem in statu Matto Grosso reipublicae Brasilianae".

Alguns fatos marcantes de seu governo foram assim relatados por Cruz (2012): 1. Ele mesmo pediu e foi atendido por Dom Bosco, que enviou os salesianos e as salesianas para a Diocese. 2. Para acolher as meninas inválidas, ele construiu o Asilo Santa Rita. 3. Trabalhou com muito empenho na construção da Igreja do Bom Despacho, que tinha como modelo a Igreja de Notre Dame de Paris.

\subsubsection{O segundo Arcebispo Dom Francisco de Aquino Corrêa}

O segundo Arcebispo de Cuiabá foi o Padre Francisco de Aquino Corrêa-SDB, que governou de 1922 a 1956. Cometti (1993) relata que a nomeação do Padre Francisco como Bispo Auxiliar da Arquidiocese de Cuiabá 
deu-se no ano de 1914. Sua Sagração Episcopal realizou-se no dia 01 de Janeiro de 1915, na Catedral do Senhor Bom Jesus de Cuiabá.

Dom Aquino deu continuidade ao desmembramento da Arquidiocese, criando as Prelazias de Diamantino (1932) e de Chapada dos Guimarães (1938). No campo pastoral, foi um pastor muito zeloso:

Empenhou-se em visitas pastorais à Arquidiocese, pregou sem cessar a palavra de Deus, fundou Associações, tais como a Associação do Senhor Jesus, a Liga dos Apóstolos da Caridade, Fé e Alegria, formou o patrimônio da Igreja de Cuiabá, cobriu o Santuário do Bom Despacho, construiu casas paroquiais e a residência dos arcebispos. Reabriu o Seminário, sendo o Noviciado e Estudantado Filosófico dos Salesianos. Incentivou a vida espiritual da arquidiocese e deu nova vida e impulso ao seminário. (CRUZ, 2012, p. 35).

No ano de 1950, o Padre Antônio Campelo de Aragão- SBD, foi nomeado Bispo Auxiliar da Arquidiocese de Cuiabá. Sua Sagração Episcopal realizou-se na Catedral de Fortaleza, CE. Nos sete anos em que esteve na diocese, "revelou-se um Pastor incansável, dinamizando os setores pastorais e sociais, visitava as famílias e ia de cidade em cidade, de movimento em movimento. Em todos os setores da sociedade adentrou para evangelizar e anunciar a Palavra de Deus" (CRUZ, 2012, p. 37). Em 1957, foi transferido para ser o Bispo de Petrolina, PE.

\subsubsection{O terceiro Arcebispo Dom Orlando Chaves}

Dom Orlando Chaves - SDB, desde 1948, era Bispo de Corumbá e foi nomeado Arcebispo de Cuiabá em 1956, enquanto todo o povo do Estado de Mato Grosso ainda chorava a perda Dom Aquino. A posse ocorreu no ano seguinte, em 1957, e seu governo durou até o ano de 1976, vindo a falecer no ano de 1981.

Entre seus feitos, se destacam os "festejos do Centenário do Seminário da Conceição; início das construções do Seminário de Cristo Rei; derruba para reconstruir a nova Catedral que seria condecorada pelo Papa Paulo VI com o título de Basílica; inauguração da Rádio Difusora Bom Jesus" (CRUZ, 2012, p. 41). 


\subsubsection{O quarto Arcebispo Dom Bonifácio Piccinini}

O quarto Arcebispo de Cuiabá foi Dom Bonifácio Piccinini - SDB. No ano de 1975, Padre Bonifácio Piccinini era o reitor do Seminário Menor de Lavrinhas, SP, foi nomeado Arcebispo Titular de Torres de Bizacena e Coadjutor com direito à sucessão de Dom Orlando Chaves. Peraro (2008) conta que, no mesmo ano em que foi nomeado bispo, Dom Bonifácio realizou a celebração de sua Sagração Episcopal na cidade de Lavrinhas. Seu governo à frente da Arquidiocese de Cuiabá perdurou até o ano de 2004. Atualmente, como Bispo Emérito, continua presente no serviço pastoral principalmente atendendo confissões nas diversas paróquias que o convidam diariamente para a administração desse importante sacramento.

Aos 05 de outubro de 1975, tomou posse na Catedral Basílica de Cuiabá. Em 1976, quando Dom Orlando completou os 75 anos de idade, mesmo conservando o título de Arcebispo, entregou o governo da Arquidiocese a Dom Bonifácio, que a assume como Administrador Apostólico Sede Plena.

Em 1981, após a morte de Dom Orlando, Dom Bonifácio sucedeu-o como Arcebispo. Seu dinamismo apostólico estimulou a criação de dezenas de novas comunidades, sobretudo nas zonas periféricas da grande Cuiabá. Acompanhou pessoalmente a construção e reforma de várias capelas, igrejas e centros de evangelização e proporcionou a construção do Studio Eclesiástico Dom Aquino Corrêa (SEDAC).

\subsubsection{O quinto Arcebispo Dom Milton Antônio dos Santos}

O quinto e atual Arcebispo de Cuiabá é Dom Milton Antônio dos Santos - SDB. Eleito bispo da diocese de Corumbá no ano 2000, no mesmo ano foi Sagrado Bispo. Cruz (2012) relata que, em 2003, Dom Milton foi nomeado Arcebispo Coadjutor da Arquidiocese de Cuiabá e, em 2004, sucedeu a Dom Bonifácio como Arcebispo Metropolitano de Cuiabá. Com a morte de Dom Franco Dalla Valle, bispo da Diocese de Juína, foi nomeado administrador apostólico daquela diocese, entre o período de 2 de agosto de 2007 a 12 de novembro de 2008.

Dom Milton, desde quando assumiu a Arquidiocese, tem aplicado um sistema inovador em seu governo. A partir do Sínodo Arquidiocesano 
(2004-2009), "realizou as visitas pastorais em toda a Arquidiocese e criou novas paróquias. Percebendo-se a urgência de a Igreja apresentar, da meIhor maneira, sua administração e contabilidade, fez-se a unificação, ou seja, centralização da prestação de contas das Igrejas na Cúria" (NOGUEIRA, 2008, p. 31). O Arcebispo montou, então, uma equipe de leigos capacitados, descentralizando o poder decisório em algumas situações. A nova gestão é marcada pela tríplice fase do staff:

A informática, onde o staff vai apenas apresentar as informações ao titular da linha para mantê-lo informado em vista de posteriores tomadas de decisões corretas; a de aconselhamento indica soluções, argumenta, convence; a de supervisão que, por procuração, supre o gerente na gerência de alguma atividade especializada, passa a exercer uma autoridade de linha, porque essa função abrange o direito de dar ordens. (CRUZ, 2012, p. 66)

\section{A PASTORAL DA ARQUIDIOCESE}

Para melhor compreender tanto os desafios quanto as ações pastorais, é necessário situar e identificar a Arquidiocese de Cuiabá, pois ela é uma das maiores do Brasil em extensão, possuindo as seguintes características geográficas:

Superfície é de $24.542 \mathrm{~km}^{2}$ com 27 paróquias, sendo 13 no interior e 14 na capital, e possuindo no geral uma população de 830.562 habitantes, calcula- se que a população seja de, aproximadamente, 606.310 fiéis. Os municípios que constituem a Arquidiocese são: Acorizal, com a população estimada em

5.530 hab.; Barão de Melgaço, com 7.619 hab.; Cuiabá, com 526.831 hab.; Jangada, com 8.058 hab.; Nobres, com 14.862 hab.; Rosário Oeste, com

18.031 hab.; Santo Antônio de Leverger, com 19.197 hab.; e Várzea Grande com 230.307 hab. (CRUZ, 2012, p. 31).

A estimativa de católicos é de 606.310 pessoas. As fronteiras da Arquidiocese de Cuiabá são as seguintes: ao leste com a Prelazia de Paranatinga, MT, ao oeste com a Diocese de São Luís de Cáceres, MT, ao norte com a Diocese de Diamantino, MT, e ao sul com a Diocese de Rondonópolis, MT. 


\subsection{Projeto pastoral - o Sínodo Arquidiocesano}

O projeto pastoral da Arquidiocese é condensado nas Diretrizes do Sínodo Arquidiocesano. "O Sínodo diocesano é uma assembleia de sacerdotes e de outros fiéis da Igreja particular escolhidos, que auxiliam o Bispo diocesano para o bem de toda a comunidade diocesana" (CONGREGAÇÃO DA DOUTRINA DA FÉ, 2001, can. 460).

O processo sinodal nasceu da vontade do Arcebispo Dom Milton dos Santos e se dividiu em 6 fases, sendo articulado do ano de 2004 ao ano de 2012. Santos (2012) afirma que esse processo teve uma participação geral de mais de 20 mil pessoas, que foram envolvidas direta ou indiretamente: 1 a fase: a conscientização; 2 a fase: grupos de reflexão; 3 a fase: fase da redação; 4 a fase: I Congresso Eucarístico e Centenário da Arquidiocese - Visitas Pastorais pós-Sínodo; 5 a fase: multiplicadores leigos para repassar os documentos às lideranças; 6a fase:Assembleias arquidiocesanas.

O método escolhido para a confecção das Diretrizes é o Ver (traz diagnósticos da realidade) - Julgar (traz orientações) - Agir (aponta pistas). Este método possui um caráter trinitário em sua essência pois busca ver com os olhos do Pai, julgar como o Filho julgaria e agir sob a ação do Espírito Santo:

O método está ligado à maneira de ser Igreja, e ajuda no processo de pastoral de conjunto, fazendo VER como comunidade, JULGAR como comunidade e AGIR como comunidade. A Igreja, sem preocupar-se com preocupar-se com suspeitas alarmistas valeu-se do método para expressar sua prática de fé, especificar sua missão e fazer uma profunda reflexão teológica". (PROJETO ALEGRANDO, s.d.).

As diretrizes são o detalhamento no pós-sínodo da ação pastoral e evangelizadora, como a regulamentação do documento do sínodo. Até o presente momento, o documento sinodal deu origem a dois volumes de diretrizes: primeiro volume A formação dos Agentes-Catequistas e Sacramentos da Iniciação Cristã e, no segundo volume, A Pastoral Familiar e o Sacramento do Matrimônio.

No primeiro volume, A formação dos Agentes-Catequistas e Sacramentos da Iniciação Cristã, possuem 15 capítulos divididos em quatro partes. Santos (2012) narra que a primeira parte é constituída de quatro capítulos e abrange da definição de catequese à formação dos catequistas da 
arquidiocese. Enfatiza a formação orgânica e contínua dos catequistas, bem como a unidade doutrinária da catequese (que passa por um conhecimento do Diretório Nacional da Catequese). Mas a grande novidade e impulso das diretrizes, apontada por Santos (2012), é o incentivo da Arquidiocese em assumir o Ministério de Catequista com cursos de preparação e investidura solene na comunidade.

A segunda parte é constituída de nove capítulos e discorre entre: a constatação da realidade paroquial (desafios e virtudes encontradas tanto nos catequistas, quanto nos catequizandos e a estrutura que a paróquia oferece para a realização dos encontros), definições sacramentais, orientações tanto para os encontros quanto para os momentos celebrativos dos sacramentos do Batismo, Confirmação, Comunhão e Confissão. É muito salientado, por Santos (2012), o envolvimento das famílias no percurso catequético, a ponto de incentivar os catequistas a visitarem os pais dos catequizandos e proporem celebrações nas quais os pais participem. Insiste-se como proposta de inserção na vida da comunidade, que seja realizado para os crismandos um tirocínio, na última etapa da crisma, em alguma pastoral da comunidade. Além de pedir aos párocos que façam os investimentos necessários para a aquisição de materiais pedagógicos e formação permanente com os catequistas, o documento toca em um ponto muito particular, que é assegurar que os fiéis portadores de necessidades especiais possam receber "uma catequese apropriada em seus recursos e conteúdo" (SANTOS, 2012, n. 28).

Faz-se presente nessa parte das diretrizes narrada por Santos (2012), o decreto da Penitenciária Apostólica que concede a Indulgência plenária por sete anos (2010-2017) a quem visitar devotamente o Santuário Eucarístico de Nossa Senhora do Bom Despacho, em Cuiabá. Para o Sínodo, é muito importante que a arquidiocese viva esse aspecto eucarístico de forma perene: "A Arquidiocese de Cuiabá viverá sempre mais em Eucaristia fazendo da Adoração contínua ao Santíssimo Sacramento na Igreja de Nossa Senhora do Bom Despacho" (SANTOS, 2012, n. 30).

A terceira parte é composta de somente o capítulo 14, o qual apresenta, avalia e orienta a utilização do sistema data-center para a administração pastoral, contábil e patrimonial on-line da arquidiocese. Demonstra a necessidade que se tem para que a Arquidiocese deva estruturar-se, de 
maneira organizada como uma empresa. E nesse caminho, propõe-se uma "Arquidiocese-net... é necessário desenvolver um Sistema de dados integrado e compartilhado, isto é, os Sistemas integrados necessitam de interligação física de computadores em rede (net)" (SANTOS, 2012, n. 40).

A quarta e última parte é constituída pelo capítulo 15, e é a conclusão, onde se define a palavra diretriz, incentiva-se a segui-la e confia-se à ação do Espírito Santo e a Nossa Senhora para que este documento alcance os objetivos.

O segundo volume As Diretrizes 2014-2019 para a Pastoral Familiar e o Sacramento do Matrimônio, entra em contato com esse tema muito caro e que hoje possui questões candentes no campo civil e religioso. 0 documento não foi dividido em capítulo, mas a sua estrutura permite uma categorização em três partes e um apêndice que é ligado à terceira parte.

A primeira parte inicia com uma reflexão sobre a mutação que, por força das mudanças da lei civil, atingem o significado da palavra família, tal como "projeto de leis que pretendem reconhecer, como entidade familiar, a união estável entre duas pessoas do mesmo sexo com o objetivo de constituição familiar" (SANTOS, 2013, p. 6). Evidenciando a situação de perigo que as famílias enfrentam, Santos (2013) enfatiza que as diretrizes demonstram a importância da instituição familiar sadia (união estável do homem com a mulher vinculados pelo matrimônio) para a sociedade e para a Igreja, e a urgência de expandir as Pastorais afins à família e envolver as famílias, como igreja doméstica, no processo de evangelização para que seja atuante e protagonista da catequese.

A segunda parte trata de ações ao nível: pré-matrimonial, pós-matrimonial, casos especiais e informações práticas para o sacramento do matrimônio. O texto traz medidas misericordiosas e pastorais na atenção aos casais de segunda união, buscou a integração do casal na comunidade. Existe a preocupação para que a Pastoral Familiar não se esqueça das pessoas que vivem sozinhas, separadas, divorciadas e continuam sendo famílias.

A terceira parte do documento transcreve os números de 224 a 243 da Conferência Nacional dos Bispos do Brasil (2005), intitulado Diretório da Pastoral Familiar sobre situações delicadas dos separados e divorciados. Traz também um texto de Falcão de Barros (2013) intitulado 'Os sacramentos 
da iniciação cristã administrados aos adotados por pessoas do mesmo sexo que vivem em união estável', que traz "um resumido compêndio de algumas indicações teológicas pastorais e jurídicas para os clérigos e leigos do nosso país sobre a atitude pastoralmente recomendada e canonicamente devida dos que devem acolher e dialogar com as pessoas do mesmo sexo que vivem em união estável, quando elas procurarem a Igreja para pedir os sacramentos da Iniciação Cristã para os seus adotados" (SANTOS, 2013, p. 41). Esse texto também é a base para o apêndice das Diretrizes, uma vez que continua o argumento de Falcão de Barros, focando, porém, em orientações para os Sacramentos de Iniciação Cristã.

As diretrizes trazem, antes da conclusão, o texto sobre Diretrizes Administrativas, que já eram presentes no 1 ㅇv volume, e não possuem nenhuma modificação. E, finaliza-se com a conclusão, na qual se ressalta que, apesar dos assaltos que a família sofre, somos chamados a caminhar em comunidade encontrando caminhos seguros, iluminando essas trevas que tentam nos assolar e, para isso, as diretrizes intentam oferecer uma linha para: "cuidar deste santuário da vida - a Família; defender esta célula primeira e vital da sociedade; ajudar as famílias a serem Igreja Doméstica" (SANTOS, 2013, p. 81).

As diretrizes constituem um documento muito virtuoso, pois demonstram uma visãode Igreja, um conceito eclesiológico em que cada católico se sinta protagonista na arquidiocese. A questão prática das Diretrizes, porém, revela um ponto que precisa ainda ser assumido como plano global, pois persiste a compreensão de uma Igreja identificada substancialmente com o clero e considerada como um local de prestação de serviços religiosos.

As diretrizes para a Arquidiocese de Cuiabá oferecem uma linha de ação que abrange o documento conclusivo tanto em seu primeiro volume, $A$ formação dos Agentes-Catequistas e Sacramentos da Iniciação Cristã, quanto no segundo volume, A Pastoral Familiar e o Sacramento do Matrimônio, e que estão presentes no documento sinodal. O documento oficial do Sínodo é mais amplo, enquanto as diretrizes têm por objetivo serem mais específicas e práticas.

E, nessa praticidade, consegue-se exprimir de maneira correta o contexto arquidiocesano com seus desafios e recursos, priorizando a possibilidade 
de realização de atos concretos, não sendo fechados em si mesmo, as diretrizes propõem um caminho unitário, mas não uniforme. Justamente por isso, as diretrizes pressupõem a confecção do Projeto Pastoral em cada paróquia, pois seria a maneira real de como desenvolver e atingir as metas propostas. Com as diretrizes em mãos, os párocos podem ter o farol para guiar a sua paróquia, no processo de formação do povo de Deus de maneira orgânica na arquidiocese.

\subsection{Organização pastoral}

A organização da Pastoral Arquidiocesana tem que ser compreendida a partir do Sínodo de 2004. A ideia do Sínodo surgiu a partir das últimas palavras de Dom Bonifácio na apresentação doXIV Plano de Ação Evangelizadora 'Ser Igreja no Novo Milênio' 2002- 2004: “Vinte e sete anos de Assembleias constituem um bom treinamento! Estaria, a Arquidiocese, amadurecendo para a celebração de um futuro síNODO ARQUIDIOCESANO? É uma esperança!..." (PICCININI, 2002, p. 5).

Toda a Organização da Pastoral advém do Sínodo e da nova compreensão de pastoral que passa pela internet e, consequentemente, com o surgimento de uma nova espiritualidade "antenada com as inovações da virada do século se utiliza de todos os canais de comunicação, e, especialmente, tem em mãos um computador" (SANTOS, 2012, n. 39). Hoje toda a Pastoral se dá em volta da Internet e Intranet.

Isso quer dizer que a Arquidiocese acontece através de uma Intranet, ou seja, as paróquias e as pessoas estão unidas pela net, gerando um organizado sistema interligado de informações. Por exemplo: Todas as folhas de pagamento das paróquias são geradas na sede da Arquidiocese e distribuídas para as paróquias através da Intranet; ou o compartilhamento de material formativo para os leigos.

Esse novo modelo é retratado na imagem abaixo, a qual evidencia esta organização pensada na pessoa: 


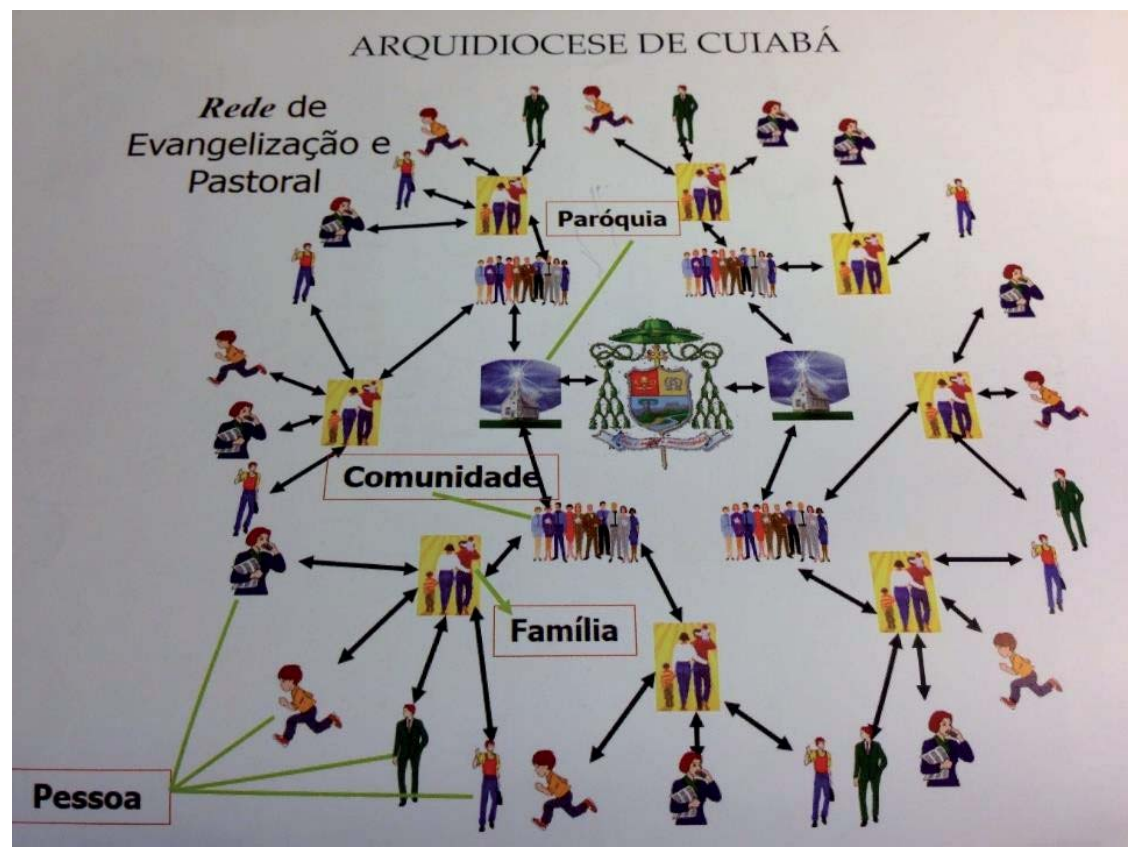

De fato, são cinco palavras chaves para a compreensão: pessoa, família, comunidade, paróquia e arquidiocese. A Arquidiocese fica no centro e depende da pessoa, pois é esta última, que está dentro de uma família que pertence a uma comunidade, e esta comunidade que, por sua vez, pertence a uma paróquia, que pertence à Arquidiocese. Frisa-se que isto é o Sínodo, este andar no único Caminho que é Jesus, tudo interligado, tudo via net.

"Todo tempo da realização do Sínodo foi o início de uma aprendizagem: sermos casa e escola da comunhão! Isto significa sermos uma Arquidiocese-net... é necessário desenvolver um sistema de dados integrado e compartilhado, isto é, os Sistemas integrados necessitam de interligação física de computadores em rede (net)" (SANTOS, 2008, n. 07). A consequência prática é o empenho da Arquidiocese em ser Igreja-comunhão, uma rede-comunhão, onde todos (sacerdotes, religiosos e religiosas e leigos) caminhem juntos como discípulos missionários, compartilhando ideias e trabalhando juntos para superação de dificuldades.

A parte organizativa da Arquidiocese conta com pessoas e secretarias que auxiliam e assessoram o arcebispo em seu governo, conforme elenca Santos (2016) no seguinte quadro: 


\begin{tabular}{|c|c|c|c|}
\hline $\begin{array}{l}\text { Secretaria / } \\
\text { Chancelaria }\end{array}$ & Cidade & Email & Usuário \\
\hline Arcebispo de Cuiabá & Cuiabá & dmilton@cuiabaarquidiocese.net & Dom Milton \\
\hline Fale com Arcebispo & Cuiabá & falecomarcebispo@cuiabaarquidiocese.net & Dom Milton \\
\hline Vigário Geral & Cuiabá & pe.deusdedit@cuiabaarquidiocese.net & Pe. Deusdédit \\
\hline Economato & Cuiabá & pe.julio@cuiabaarquidiocese.net & Pe. Júlio \\
\hline $\begin{array}{l}\text { Coordenador da } \\
\text { Pastoral }\end{array}$ & Cuiabá & pastoral@cuiabaarquidiocese.net & Pe. Fábio \\
\hline Secretaria da Cúria & Cuiabá & secretaria@cuiabaarquidiocese.net & Sra. Edilse \\
\hline Coordenador do Site & Cuiabá & mendes.a@terra.com.br & Sr. Alexandre \\
\hline $\begin{array}{l}\text { Departamento de } \\
\text { Arquivos da Cúria }\end{array}$ & Cuiabá & pe.felisberto@cuiabaarquidiocese.net & Pe. Felisberto \\
\hline $\begin{array}{l}\text { Departamento } \\
\text { Contábil }\end{array}$ & Cuiabá & contabilidade@cuiabaarquidiocese.net & $\begin{array}{l}\text { Sr. Ilson } \\
\text { Pimenta }\end{array}$ \\
\hline R.H. Mitra Cuiabá & Cuiabá & rh@cuiabaarquidiocese.net & $\begin{array}{l}\text { Sra. Léia } \\
\text { Pimenta }\end{array}$ \\
\hline $\begin{array}{l}\text { Setor de T.I. Mitra } \\
\text { Cuiabá }\end{array}$ & Cuiabá & ti@cuiabaarquidiocese.net & Sr. Gilberto \\
\hline $\begin{array}{l}\text { Tribunal Interdioce- } \\
\text { sano de Cuiabá }\end{array}$ & Cuiabá & tribunalcuiaba@yahoo.com.br & Pe. Evandro \\
\hline
\end{tabular}

A pastoral arquidiocese é muito ativa e rica em grupos e movimentos, fruto de uma primavera de evangelização e carismas de diversas ordens e congregações religiosas. Percebem- se atividades importantes que valorizam a fé popular e as tradições que contêm os valores religiosos do povo cuiabano. Apesar da diversidade religiosa presente, um outro elemento utilizado é o sentido de pertença que a religiosidade popular codifica na pessoa, ou seja, independente da religião que a pessoa pratica, em dias de festa de São Benedito, ela se sente convidada e intimada a participar até mesmo nas funções religiosas.

Os grupos e movimentos promovem uma importante socialização religiosa, conseguindo englobar uma grande ou todas as camadas que abrangem a Igreja, isto é, entre seus participantes existem aqueles grupos/movimentos para os mais tradicionalistas, ou para os mais místicos, ou para os que querem trabalhar em causas sociais e/ou políticas e até mesmo grupos que são críticos, ou seja, que são católicos, frequentam os sacramentos, mas que se distanciam da igreja instituição quando não concordam com os valores. 
O Coordenador da Pastoral Arquidiocesana chama-se Pe. Fábio Silva de Oliveira, que trabalha animando e sendo o centro de referência e unidade das pastorais. Cada pastoral escolhe o seu responsável sem nenhum tipo de indicação por parte do Arcebispo. Os coordenadores e coordenadoras são os primeiros responsáveis das animações "in loco", fazendo que as experiências, as informações, os desafios e conquistas sejam partilhados, favorecendo, assim, o diálogo e o crescimento de todas as atividades, dando um grau de excelência para a pastoral da Arquidiocese.

Hodiernamente as Pastorais da Arquidiocese são: "Pastoral Catequética; Pastoral Familiar; Pastoral da Pessoa Idosa; Pastoral da Saúde; Pastoral da Sobriedade; Pastoral Carcerária; Pastoral de Rua; Setor Juventude; Pastoral da Comunicação; Pastoral do Menor; Pastoral da Criança; Pastoral do Dízimo; Pastoral Vocacional" (SANTOS, 2014, p. 89).

Atualmente os Movimentos da Arquidiocese: "Apostolado da Oração; São Vicente de Paulo; Legião de Maria; Movimento Sacerdotal Mariano; Ministros Extraordinários da Sagrada Comunhão - MESC; Renovação Carismática Católica - RCC; Movimento de Cursilhos de Cristandade-MCC; Encontro de Casais com Cristo; Liga dos Apóstolos; OVISA / JOVISA" (SANTOS, 2014, p. 92). Nota-se também a presença do SEGUE-ME e dos CAMPISTAS, que ganham muita notoriedade diante dos fiéis em Cuiabá, mas que ainda carecem de uma organização arquidiocesana.

\section{CONSIDERAÇÕES FINAIS}

Ressalta-se que, por motivos bibliográficos, a apresentação da história da fundação da Arquidiocese foi realizada em grande parte através do ponto de vista de religiosos, bispos e arcebispos que fizeram e fazem parte desse processo, guiando a comunidade católica com amor e verdade. Alguns elementos bibliográficos, até o momento desconhecidos, foram revelados e agora podem ser anexados como fonte segura de pesquisa.

Os desafios religiosos, sociais e políticos que o tempo presente, cheio de caos, dificuldades e corrupção, implica sobre a população cuiabana, minam a sua esperança diante de uma visão de mundo escuro, aproveitador e sofredor. A cidade está para completar seus trezentos anos de fundação, mas a dura realidade de insegurança e de injustiça atormenta o povo já incrédulo 
na política e em outras instituições públicas.

Fiel à sua história, a Arquidiocese de Cuiabá goza perante a sociedade cuiabana de prestígio e confiança, pois continua sendo coerente e forte em seus valores e princípios; denunciando profeticamente a opressão, o descaso e o abuso aos pobres e aos necessitados; defendendo a dignidade da vida humana e proclamando o amor de Deus por cada um de nós. Uma verdadeira fonte de esperança, alívio e conforto para toda a população.

\section{REFERÊNCIAS}

ARQUIVO DA CÚRIA METROPOLITANA DE CUIABÁ. Livro de Tombo. Cuiabá: [s.n.], 1967.

BENTO XIV. Candor Lucis Aeternae. In: MARTINIS Raffaele de. Iuris pontificii de Propaganda Fide. Pars prima. Romae: [s.n.], 1890. Tomo III.

BRASIL ESCOLA. História de Cuiabá. [s.d.]. Disponível em: <http:// cidadebrasileira.brasilescola.com/mato-grosso/historia-cuiaba.htm>. Acesso em: 7 out. 2014.

COMETTI, Pedro. Apontamentos da história eclesiástica de Mato Grosso. Paróquia e Prelazia. Cuiabá: Gráfica Cosindio, 1996. v. 1.

. Dom Aquino Corrêa. Vida e obra. Cuiabá: Gráfica Cosindio, 1993.

CONFERÊNCIA NACIONAL DOS BISPOS DO BRASIL. Documentos da CNBB 79. Diretório da Pastoral Familiar. 7. ed. São Paulo: Paulinas, 2005.

CONGREGAÇÃO DA DOUTRINA DA FÉ. Código de Direito Canônico. São Paulo: Loyola, 2001.

CRUZ, FelisbertoSamoel. Arquidiocese de Cuiabá. História e Vida 1910-2010. Cuiabá: Carlini \& Caniato, 2012.

DIÁRIO DE CUIABÁ. Massacres marcaram primeiros contatos. [s.d.]. Disponível em: $<$ http://www.diariodecuiaba.com.br/especial2. php?cod=6\&mat=15232>. Acesso em: 7 out. 2014.

FALCÃO DE BARROS, Dom José Francisco. 51a Assembleia Geral da CNBB. Discurso: os sacramentos da iniciação cristã administrados aos adotados por pessoas do mesmo sexo que vivem em união estável. Brasília: CNBB, 2013.

LEÃO XII. Bolla Sollicita Catholici Gregis Cura. In: Bullarii romani continuatio. Romae: [s.n.], 1854. Tomo XVI.

MENDES, Alexandre. Dados históricos. [s.d.]. Disponível em: <http://www. arquidiocesecuiaba.org.br/index. phpoption=com_content\&task=view\&id=3>. Acesso em: 7 out. 2014. 
NOGUEIRA, Luiz Rogério. Gestão administrativa e financeira eclesiástica. Petrópolis, RJ: Vozes, 2008.

PERARO, Maria Adenir (Org.). Arquidiocese de Cuiabá. Seminário do jubileu da Igreja Católica e os cem anos da Arquidiocese de Cuiabá. Rumo aos 100 anos. Cuiabá: Cúria Metropolitana-Expediente, 2008.

PICCININI, Bonifácio. XIV Plano de Evangelização. Ser Igreja no Novo Milênio 20022004. Cuiabá: Cúria Metropolitana-Expediente, 2002.

PIO X. Bula Novas Constituire. In: AAS 2 (1910) 290.

PÓvOAS, Lenine C. História geral de Mato Grosso. Cuiabá: CIP, 1995. v. 1.

PROJETO ALEGRANDO. Comissão para Animação Bíblico-Catequética-Pastoral da Crisma. [s.d.]. Disponível em: <http://projetoalegrando.webnode.com.br/o-projeto/ ver-julgar-e-agir/>. Acesso em: 24 out. 2014.

SANTOS, Milton Antônio. Calendário Arquidiocesano de Pastoral - 2016. Cuiabá: Cúria Metropolitana-Expediente, 2016.

. Calendário Arquidiocesano de Pastoral-2014. Cuiabá: Cúria MetropolitanaExpediente, 2014.

. As diretrizes 2014-2019 para a Pastoral Familiar e o Sacramento do Matrimônio. Cuiabá: Cúria Metropolitana-Expediente, 2013. v. 2.

. Diretrizes do Sínodo Arquidiocesano de Cuiabá. Formação dos AgentesCatequistas e Sacramentos da Iniciação Cristã 2012-2018. Cuiabá: Cúria Metropolitana-Expediente, 2012. v. 1.

. Sínodo Arquidiocesano de Cuiabá. Documento Conclusivo. 3 doc. Cuiabá: Cúria Metropolitana-Expediente, 2008. 